\title{
PENSAMENTO E RACIOCÍNIO ESTOCÁSTICO NA BNCC DE EDUCAÇÃO INFANTIL: INFERÊNCIAS PARA O LETRAMENTO ${ }^{1}$
}

\section{Stochastic Thinking and Reasoning in the Children's Education BNCC: Inferences for Stochastic Literacy}

Thuanne Souza Jahnke ${ }^{2}$

João Carlos Pereira de Moraes $^{3}$

Ana Lúcia Pereira ${ }^{4}$

\begin{abstract}
Resumo: Com o presente artigo, visamos analisar possíveis aproximações e potencialidades sobre o trabalho com o pensamento e o raciocínio estocástico, com os objetivos de aprendizagem e desenvolvimento (OAD) presentes na BNCC de Educação Infantil. A pesquisa é de abordagem qualitativa, realizada a partir de uma análise documental. A coleta e a análise de dados se deram a partir dos OAD do referido documento. Nossos resultados apontam que essa aproximação é possível a partir dos $4^{\circ}$ e $5^{\circ}$ campos de experiência da Base Nacional Comum Curricular para a Educação Infantil, que estão associados aos conteúdos de Combinatória, Estatística e Probabilidade do currículo de Matemática. Como resultados, evidenciamos ainda a importância do desenvolvimento do pensamento estocástico nas crianças pequenas para que compreendam o mundo a sua volta e saibam organizar informações por meio de tabelas, gráficos e outras formas de registros. Como potencialidades, destacamos que os OAD presentes na BNCC apresentam-se como fortes possibilidades didático-metodológicas para a construção do Letramento Estocástico.
\end{abstract}

Palavras-chave: Letramento Estocástico. BNCC. Educação Infantil.

\footnotetext{
Abstract: This article aims to analyze possible approaches and potentialities about working with stochastic thinking and reasoning, with the learning and development goals (objetivos de aprendizagem e desenvolvimento (OAD)) present in the BNCC of Early Childhood Education. The research has a qualitative approach, carried out from a documentary analysis. The collection and analysis of data took place from the (OAD) of the referred document. Our results indicate that this approximation is possible from the 4th and 5th fields of experience of

${ }^{1}$ A autora Ana Lúcia Pereira agradece à Fundação Araucária pela bolsa produtividade em Pesquisa.

2 Mestranda em Educação e Licencianda em Pedagogia (UNIPAMPA). Licenciada em Letras - Português, Espanhol e Respectivas Literaturas (UNIPAMPA) e Especialista em Alfabetização e Letramento (FESL). Orcid: https://orcid.org/0000-0003-4460-0393. E-mail: thuannejahnke.aluno@unipampa.edu.br.

${ }^{3}$ Professor do PPGECEM (UEPG) e PPGEdu (UNIPAMPA). Doutor em Educação pela Universidade de São Paulo (USP), Mestre em Educação Científica e Tecnológica (UFSC), licenciado em Matemática (UENP) e Pedagogia (UEM). Orcid: https://orcid.org/0000-0001-9513-018X. E-mail: joaomoraes@unipampa.edu.br.

${ }^{4}$ Doutora em Ensino de Ciências e Educação Matemática pela Universidade Estadual de Londrina (UEL). Professora Adjunta no Departamento de Matemática e Estatística e nos Programas de Pós-Graduação em Educação e em Ensino de Ciências e Educação Matemática na Universidade Estadual de Ponta Grossa (UEPG). É editora associada dos periódicos Frontiers in Psychology e Frontiers in Education. Bolsista produtividade da Fundação Araucária. Orcid: https://orcid.org/0000-0003-0970-260X. E-mail: anabaccon@uepg.br.
} 
the Base Nacional Comum Curricular for Early Childhood Education, and it is associated with the contents of combinatorics, statistics and probability of the mathematics curriculum. As a result, the importance of the development of stochastic thinking in young children is also evident so that they understand the world around them and know how to organize information through tables, graphs and other forms of records. As potentialities, we can highlight that the Objetivos de Aprendizagem e Desenvolvimento (OAD) present in BNCC, present themselves as strong didactic-methodological possibilities for the construction of Stochastic Literacy.

Keywords: Stochastic Literacy. BNCC. Early Childhood Education.

\section{Introdução}

No contexto de Educação Infantil, faz parte do papel do pedagogo pensar processos de letramento a partir de diferentes modos de pensar e viver o mundo. Isto é, o professor que trabalha nessa etapa de ensino necessita dialogar com diversos campos do conhecimento para promoção do olhar crítico na criança sobre as práticas sociais de leitura e intervenção na realidade. Nesse sentido, o campo da Educação Matemática não fica alheio a isso, muito menos questões no interior deste, como o pensamento e raciocínio estatístico.

Por outro lado, as práticas de Educação Infantil são norteadas por questões curriculares nacionais, que mobilizam e organizam o ensino nos espaços escolares. Entre esses elementos, levantamos a Base Nacional Comum Curricular (BNCC) como um dos pressupostos organizadores do currículo na Educação Infantil. Sendo assim, o Letramento e a nova BNCC devem caminhar juntos na produção de uma educação de qualidade para crianças de 0 a 5 anos de idade.

Com tal ideia em mente, com este artigo visamos analisar possíveis aproximações e potencialidades para o trabalho com o pensamento e o raciocínio estocástico com os objetivos de aprendizagem e desenvolvimento (OAD) presentes na BNCC de Educação Infantil. Para tanto, realizamos uma análise documental dos OAD, suscitando possibilidades para o letramento no contexto da primeira etapa de ensino da Educação Básica.

O artigo está organizado nos seguintes tópicos: (1) Infância e Educação Infantil, dividida em dois momentos: (a) Breve debate sobre teorias da Infância e (b) Educação Infantil e a BNCC; (2) Educação Matemática na Educação Infantil e a ideia do Letramento, que se divide em: (a) letramento, (b) letramento estatístico, (c) letramento probabilístico e (d) letramento estocástico; (3) Abordagem metodológica; (4) Raciocínio e Pensamento Estocástico na Educação Infantil: associações com a BNCC; e, por fim, (5) Considerações finais.

\section{Infância e Educação Infantil}

Para iniciar o nosso estudo, marcamos nas seções abaixo dois posicionamentos da pesquisa. No primeiro deles, apontamos a perspectiva da sociologia da infância como proposta para pensar a infância no contexto escolar. Já, no segundo momento, nos aproximamos da BNCC como documento norteador para produção de práticas pedagógicas na Educação Infantil. 


\subsection{Breve debate sobre teorias da Infância}

O conceito de infância foi construído histórica e socialmente ao longo do tempo. Até o século XII, a criança era vista como um adulto em miniatura (ARIĖS, 1981). Os pequenos eram tratados como adultos desde o vestuário até os costumes diários. Nesse período, não existia um sentimento de infância (ARIÈS, 1981), ou seja, uma consciência de infância que diferencia a criança do adulto. Philippe Ariès (1981) aponta que somente entre os séculos XV e XVII começa a surgir um sentimento superficial pela criança, como cuidados de higiene, proteção e educação.

Nesse contexto, a creche foi criada na França em 1844 e, em 1870, expande-se internacionalmente, chegando ao Brasil com resquícios do Império. Já no período da República, surgem as primeiras instituições como creches, maternais e jardins de infância brasileiros. Segundo Kuhlmann (2000), as políticas sociais para a infância nessa época tinham um caráter assistencialista; em outras palavras, as crianças eram atendidas por entidades sociais, enquanto seus pais trabalhavam.

Essa perspectiva traduz uma concepção de infância a partir do adulto. Isto é, o trabalho com a criança emerge para atender as demandas dos adultos de espaços para deixar seus filhos. Nesse sentido, não questionamos se as crianças eram bem ou mal atendidas, mas que o papel desses espaços configurava um local para deixar os pequenos de modo seguro para seus pais.

A trajetória da Educação Infantil brasileira foi circunscrita por inúmeras transformações, principalmente a partir do século XX. Em meados de 1990, aspectos do cuidado e da educação da criança pequena começam a ser enfatizados na Educação Infantil e as propostas pedagógicas passam a favorecer o desenvolvimento natural da criança e a valorizar a experiência infantil (KUHLMANN, 2000).

A partir da década de 80, há uma retomada nos estudos sobre a infância, não apenas do ponto de vista filosófico e sociológico, mas agora direcionando-o para a educação. Esse processo de modificação pautou-se nos estudos de psicologia educacional, principalmente as abordagens piagetianas e vygostikyanas, que oportunizam pensar a criança como sujeito ativo no espaço escolar (CORSARO, 2011).

As abordagens piagetianas e vygostikyanas emergem como questionamento do modelo determinista de infância. No modelo determinista, a criança é passiva, deve ser treinada e controlada (MARCHI, 2009). Segundo Corsaro (2011), essa perspectiva divide-se em duas abordagens: a funcionalista e a reprodutivista.

[...] teorias reprodutivas e funcionalistas podem ser criticadas por sua preocupação excessiva nos resultados da socialização, pela subestimação das capacidades ativas e inovadoras de todos os membros da sociedade e por sua negligência em relação à natureza histórica e contingente da ação social e da reprodução. Em suma, esses modelos abstratos simplificam processos altamente complexos e, no processo, ignoram a importância das crianças e da infância na sociedade (CORSARO, 2011, p. 21).

O funcionalismo preparava a criança para manter a ordem e o equilíbrio social, já o reprodutivismo afirmava a desigualdade social das crianças ao discriminar o acesso a 
treinamentos e a recursos culturais. Nesse sentido, a intenção consistia em manter o status $q u o$, colocando a "ênfase nos fatores estruturais que pesam sobre ação social para a análise da capacidade de ação (agency) da criança” (MARCHI, 2009, p. 228).

Contrapondo-se a tais ideias, no modelo construtivista, a criança é vista como um sujeito ativo, capaz de aprender e construir significados, apropriando-se da sociedade (CORSARO, 2011). Nessa abordagem, encontramos a teoria de Piaget sobre o desenvolvimento intelectual e a visão sociocultural do desenvolvimento humano de Vygotsky. Embora oportunizem à criança um espaço como sujeito produtor, Corsaro (2011) discute alguns pontos fracos do modelo construtivista, ao destacar que o objetivo principal continua sendo o desenvolvimento individual.

\footnotetext{
O construtivismo oferece uma visão ativa, mas solitária, das crianças. [...] Há pouca, ou nenhuma, consideração sobre como as relações interpessoais são refletidas em sistemas culturais, ou como as crianças, por meio de sua participação em eventos comunicativos, tornam-se parte dessas relações interpessoais e padrões culturais e como os reproduzem coletivamente. [...] Outra limitação da psicologia do desenvolvimento construtivista é a preocupação exagerada com o ponto de chegada do desenvolvimento ou o percurso da criança, da imaturidade à competência adulta (CORSARO, 2011, p. 29).
}

Na concepção de Corsaro (2011), as teorias sociais da infância deram destaque ao desenvolvimento individual da criança, não considerando as relações interpessoais e culturais. Por esse ângulo, Corsaro (2011, p. 31) apresenta uma abordagem interpretativa à socialização na infância, voltando o seu olhar para as atividades práticas das crianças, para a produção e a participação na cultura de pares, em um processo de apropriação, reinvenção e reprodução.

Na reprodução interpretativa, as crianças "criam e participam de suas próprias e exclusivas culturas de pares quando selecionam ou se apropriam criativamente de informações do mundo adulto para lidar com suas próprias e exclusivas preocupações" (CORSARO, 2011, p. 31). Assim sendo, o autor assinala que o termo reprodução traz a ideia que as crianças interpretam, dão sentido e produzem mudanças culturais de maneira ativa dentro da sociedade.

Perante os argumentos suscitados acima, esse estudo apoia-se numa concepção mais sociológica de infância, utilizando dos aspectos culturais de pares e práticas sociais do conceito de reprodução interpretativa para pensar a criança no contexto escolar de Educação Infantil.

\subsection{Educação Infantil e a BNCC}

A assistência social foi o marco do contexto histórico da Educação Infantil no Brasil. A educação assistencialista para a infância visava a submissão dos trabalhadores e a aceitação da exploração social (KUHLMANN, 2000). Foi a partir da Constituição Federal de 1988 que a Educação Infantil passou a ser vista como especificidade da educação, reconhecida pela Legislação Nacional. Portanto, vemos no inciso IV do artigo 208 da Constituição que a Educação Infantil, em creche e pré-escola destinada às crianças de até 5 anos, é um dever do Estado com a educação (BRASIL, 1988). 
No Brasil, a Educação Infantil torna-se a primeira etapa da Educação Básica a partir da Lei de Diretrizes e Bases da Educação Nacional no 9394, de 1996 - LDB (BRASIL, 1996). Na LDB, encontramos na Seção II - da Educação Infantil, o artigo 29, que estabelece que "a Educação Infantil, primeira etapa da Educação Básica, tem como finalidade o desenvolvimento integral da criança até seis $^{5}$ anos de idade, em seus aspectos físico, psicológico, intelectual e social, completando a ação da família e da comunidade" (BRASIL, 1996).

Os princípios promulgados na Constituição Federal (BRASIL, 1988) e na LDB (1996) caminham no sentido de reforçar o acesso a toda a criança à Educação Infantil e, ainda, que essa oferta seja de qualidade, compreendendo os pequenos como sujeitos integrais, e em parcerias com os seus espaços sociais de convivência.

Atualmente, alguns documentos que orientam a Educação Infantil como: o RCNEI Referencial Curricular Nacional para a Educação Infantil (1998), DCNEI - Diretrizes Curriculares Nacionais para a Educação Infantil (2010) e o RCGEI - Referencial Curricular Gaúcho para a Educação Infantil (2018), o último tem como referência a Base Nacional Comum Curricular - BNCC (2017) ${ }^{6}$.

Neste estudo, pautaremos o debate a partir da BNCC de Educação Infantil. Essa proposta curricular é um documento normativo baseado em direitos e objetivos de aprendizagem que orienta as escolas da rede de ensino a elaborarem seus currículos e propostas pedagógicas para a Educação Infantil. A BNCC defende que as decisões pedagógicas devem ser conduzidas para o desenvolvimento de competências em todas as etapas da Educação Básica (BRASIL, 2017).

Na Educação Infantil, o objetivo da BNCC é ampliar as experiências, os conhecimentos e as habilidades das crianças, de forma diversificada, e proporcionar aprendizagens que complementem a educação familiar. À vista disso, a BNCC prima pela potencialização das aprendizagens e o desenvolvimento das crianças, com base no diálogo com a diversidade cultural das famílias e da comunidade. Essa perspectiva entra em consonância com o artigo $4^{\circ}$ das Diretrizes Curriculares Nacionais para a Educação Infantil (BRASIL, 2010), que define a criança como

[...] sujeito histórico e de direitos, que, nas interações, relações e práticas cotidianas que vivencia, constrói sua identidade pessoal e coletiva, brinca, imagina, fantasia, deseja, aprende, observa, experimenta, narra, questiona e constrói sentidos sobre a natureza e a sociedade, produzindo cultura (BRASIL, 2010).

A BNCC parte dos dois eixos estruturantes das práticas pedagógicas das DCNEI, que são as interações e as brincadeiras, experiências nas quais as crianças constroem e apropriam-se de conhecimento através de suas ações e interações com seus pares e com os adultos (BRASIL, 2017). Nesse sentido, nota-se o reforço da ludicidade como espaço para pensar a infância e as práticas pedagógicas ali desenvolvidas. Para tanto, a BNCC apresenta seis direitos de aprendizagem e desenvolvimento na Educação Infantil:

\footnotetext{
${ }^{5}$ Com o ensino de nove anos, a Educação Infantil passa a compreender o período de 0 a 5 anos e 11 meses.

${ }^{6}$ Não discutiremos o RCGEI - Referencial Curricular Gaúcho para a Educação Infantil (2018), porque é semelhante à BNCC. Essa similitude é uma tendência de reprodução de currículo com o objetivo de atender demandas nacionais.
} 
- Conviver com outras crianças e adultos, em pequenos e grandes grupos, utilizando diferentes linguagens, ampliando o conhecimento de si e do outro, o respeito em relação à cultura e às diferenças entre as pessoas.

- Brincar cotidianamente de diversas formas, em diferentes espaços e tempos, com diferentes parceiros (crianças e adultos), ampliando e diversificando seu acesso a produções culturais, seus conhecimentos, sua imaginação, sua criatividade, suas experiências emocionais, corporais, sensoriais, expressivas, cognitivas, sociais e relacionais.

- Participar ativamente, com adultos e outras crianças, tanto do planejamento da gestão da escola e das atividades propostas pelo educador quanto da realização das atividades da vida cotidiana, tais como a escolha das brincadeiras, dos materiais e dos ambientes, desenvolvendo diferentes linguagens e elaborando conhecimentos, decidindo e se posicionando.

- Explorar movimentos, gestos, sons, formas, texturas, cores, palavras, emoções, transformações, relacionamentos, histórias, objetos, elementos da natureza, na escola e fora dela, ampliando seus saberes sobre a cultura, em suas diversas modalidades: as artes, a escrita, a ciência e a tecnologia.

- Expressar, como sujeito dialógico, criativo e sensível, suas necessidades, emoções, sentimentos, dúvidas, hipóteses, descobertas, opiniões, questionamentos, por meio de diferentes linguagens.

- Conhecer-se e construir sua identidade pessoal, social e cultural, constituindo uma imagem positiva de si e de seus grupos de pertencimento, nas diversas experiências de cuidados, interações, brincadeiras e linguagens vivenciadas na instituição escolar e em seu contexto familiar e comunitário (BRASIL, 2017, p. 38 , grifos do documento).

Esses direitos podem ser simplificados a partir dos verbos: conviver, brincar, participar, explorar, expressar e conhecer-se. Tais direitos proporcionam à criança exercer um papel ativo em ambientes desafiadores para que consiga construir significados sobre si, os outros e o mundo social e natural (BRASIL, 2017).

Quanto à organização curricular da Educação Infantil, a BNCC sistematiza as práticas pedagógicas em campos de experiências, que "constituem um arranjo curricular que acolhe as situações e as experiências concretas da vida cotidiana das crianças e seus saberes, entrelaçando-os aos conhecimentos que fazem parte do patrimônio cultural" (BRASIL, 2017, p. 40). Ou seja, os campos de experiências podem ser percebidos como agrupamentos significantes de situações e possíveis modos de vivenciá-las. Tal agrupamento associa-se à necessidade de as práticas pedagógicas possuírem intencionalidade educativa, afastando-se da ideia que os processos de aprendizagem da criança são resultados de um desenvolvimento natural ou espontâneo. Exige-se, assim, a sistematização e organização consciente por parte do docente das intervenções que propõem.

Para tal organização, a BNCC elabora cinco campos de experiências e em cada campo são definidos os objetivos de aprendizagem e desenvolvimento (OAD). Os campos de experiências são: (1) O eu, o outro e o nós; (2) Corpo, gestos e movimentos; (3) Traços, sons, cores e formas; (4) Escuta, fala, pensamento e imaginação; e (5) Espaços, tempos, quantidades, relações e transformações (BRASIL, 2017).

Ao observarmos os campos, não consideramos que a Educação Matemática na Educação Infantil esteja detida no $5^{\circ}$ campo de experiência, uma vez que esse recorte atrelar-se-ia a uma perspectiva mais disciplinar de atuação. Contudo, para estruturação mais focalizada do trabalho que propomos, enfatizamos os objetivos de aprendizagem desenvolvimento presentes nos $4^{\mathrm{a}}$ e $5^{\mathrm{o}}$ campos, pois compreendemos que podem auxiliar-nos 
para pensar práticas pedagógicas relacionadas ao nosso objetivo de pesquisa (mais à frente, nós detalharemos esse ponto).

\section{Educação Matemática na Educação Infantil e a ideia de Letramento}

A Base Nacional Comum Curricular indica a necessidade da Educação Matemática na Educação Infantil ao propor a ampliação de experiências, conhecimentos e habilidades das crianças em diferentes espaços, tempos, fenômenos naturais e sociais. Além disso, o documento orienta que as práticas pedagógicas sejam voltadas para a observação, as diferentes formas de expressão, a manipulação de objetos, a investigação e exploração do meio, o levantamento de hipóteses e a consulta de informações (BRASIL, 2017). Essa perspectiva vincula-se à ideia de letramento matemático, definido pelo próprio documento como

[...] competências e habilidades de raciocinar, representar, comunicar e argumentar matematicamente que ajudam na estruturação de conjecturas, na formulação e na resolução de problemas em diversos contextos, com o uso de conceitos, procedimentos, fatos e ferramentas matemáticas (BRASIL, 2017, p. 266).

Nesse sentido, o letramento matemático assegura o reconhecimento de conhecimentos matemáticos como fundamentais para que o indivíduo compreenda e atue no mundo, ao desenvolver o raciocínio lógico e crítico e ao estimular a investigação (BRASIL, 2017). Nas próximas seções veremos alguns entendimentos sobre letramento e sua aproximação com o pensamento estocástico.

\subsection{Letramento}

A participação das crianças nas rotinas culturais é um aspecto fundamental da reprodução interpretativa (CORSARO, 2011), visto que as rotinas proporcionam às crianças e aos atores sociais a certeza de pertencer a um grupo social. Essa participação nas rotinas culturais começa a partir do nascimento da criança. No ocidente, no início da infância, os bebês são tratados como se fossem capazes de trocas sociais, quando as habilidades comunicativas e de linguagem da criança ainda são restritas. Com o tempo, "a atitude de como se" faz com que as crianças passem de uma limitada a uma total participação nas rotinas culturais (CORSARO, 2011, p.32).

A linguagem e a participação das crianças nas rotinas culturais permitem aos atores sociais o entendimento e o enfrentamento dos problemas da vida cotidiana. Em vista disso, a língua é essencial para a participação das crianças em sua cultura, porque é um sistema simbólico que codifica a organização cultural da sociedade, e é um instrumento que possibilita a construção e a reconstrução das realidades culturais (CORSARO, 2011). Essas rotinas culturais são elementos essenciais quando nos aproximamos de contextos de letramento.

O letramento, por sua vez, é um termo que começou a ser discutido há pouco tempo no Brasil. Seu debate emerge quando a alfabetização, saber codificar e decodificar a língua, passou a ser insuficiente para se pensar o uso social da linguagem. Ou seja, o debate sobre 
letramento toma força a partir do momento que o uso da língua nas práticas sociais torna-se elemento a ser refletido na escola, procurando envolver criticamente os sujeitos na cultura da leitura e da escrita.

Soares (2009) é uma das autoras referência nas teorizações da discussão alfabetização e letramento. Para a autora, a palavra letramento origina-se da palavra em inglês literacy, que indica o estado ou a condição do indivíduo que aprendeu a ler e a escrever de forma que consiga gerar resultados sociais, culturais, econômicos, políticos, cognitivos e linguísticos para o grupo social em que está inserido.

Ao traduzir a palavra literacy: letra-, do latim littera e o sufixo -mento, que significa o resultado de uma ação, a pesquisadora explica que é possível identificar o letramento como o resultado da ação de ensinar e aprender a ler e a escrever, o estado ou a condição que um grupo social ou um indivíduo adquirem ao apoderarem-se da escrita e da leitura. Então, Soares (2009) expõe a condição de ser letrado diferenciando-a de ser alfabetizado:

\begin{abstract}
Há, assim, uma diferença entre saber ler e escrever, ser alfabetizado, e viver na condição ou estado de quem sabe ler e escrever, ser letrado (atribuindo a essa palavra o sentido que tem literate em inglês). Ou seja: a pessoa que aprende a ler e a escrever - que se torna alfabetizada - e que passa a fazer uso da leitura e da escrita, a envolver-se nas práticas sociais de leitura e de escrita - que se torna letrada - é diferente de uma pessoa que não sabe ler e escrever - é analfabeta - ou sabendo ler e escrever não faz uso da leitura e da escrita - é alfabetizada, mas não é letrada, não vive no estado ou condição de quem sabe ler e escrever e pratica a leitura e a escrita (SOARES, 2009, p. 36).
\end{abstract}

A partir das elucidações de Soares (2009) sobre alfabetização e letramento, entendemos que o letramento abrange as práticas de leitura e de escrita em um contexto social e cultural. E essas práticas socioculturais irão permear diferentes linguagens, dependendo da função social dessa linguagem, seja oral ou escrita. A alfabetização e o letramento podem ser vistos como processos independentes e, ao mesmo tempo, interdependentes e indissociáveis (SOARES, 2003).

A alfabetização e o letramento na Educação Matemática mostram-se também como um elo de complementaridade. Podemos identificar a alfabetização matemática quando o indivíduo codifica e decodifica os números, como a ação de ler e escrever matemática, de compreender as noções básicas da matemática, ou seja, dominar o código. Já o letramento matemático acontece quando as práticas sociais da matemática são vivenciadas culturalmente. Assim, a alfabetização matemática na perspectiva do letramento leva em consideração a inserção da criança na sociedade, isto é, a compreensão da função social da linguagem matemática (BRASIL, 2014). Segundo Fonseca,

[...] as práticas sociais envolvendo quantificação, medição, orientação, ordenação ou classificação compõem os modos de usar a língua escrita e são por eles constituídas, não só porque representações matemáticas aparecem nos textos escritos ou porque nossa herança cultural nos legou modos escritos de fazer Matemática, mas porque a própria cultura escrita, que permeia e constitui as práticas matemáticas das sociedades grafocêntricas, é, em geral, permeada também por princípios calcados numa mesma racionalidade, que forja ou parametriza essas práticas matemáticas e que é por elas reforçada. (FONSECA, 2013, p.9)

A criança desde pequena tem contato com diversos suportes de linguagem como livros, jornais, folhetos, cartazes, celular, computador, etc. Encontramos a linguagem 
matemática em diferentes gêneros textuais como o bilhete, as receitas culinária e médica, o calendário, a reportagem e a notícia jornalística, a lista de supermercado, a bula de remédio, os rótulos de embalagens, etc. Tal linguagem apresenta-se em forma de números ordinais, cardinais e fracionários, elementos da geometria, medidas, tabelas, gráficos, porcentagens, algarismos romanos, dentre outros.

À vista disso, é importante explorar fontes de leitura matemática para que a criança que está entrando no processo de alfabetização e letramento conheça a diversidade de gêneros/ produções sociais, e se torne um leitor crítico ao ler e compreender a linguagem matemática. Portanto, a alfabetização matemática torna-se mais significativa quando as crianças experimentam práticas sociais de letramento matemático.

Essa vida social marcada pela cultura escrita apresenta, pois, demandas - e também oportunidades - para adultos e para crianças, por exigirem um compromisso da escola com uma alfabetização num sentido amplo que se refere à aprendizagem do sistema de escrita e também à apropriação do conhecimento sobre as práticas, sobre os usos e funções da leitura e da escrita em diversos campos da vida social. (BRASIL, 2014, p.27).

A alfabetização matemática vai além das noções básicas de aritmética ou geometria, por exemplo, porque envolve o contexto de uso dessa linguagem matemática. De que maneira podemos compreender as diferentes situações cotidianas e como podemos usar a linguagem matemática para entender e resolver problemas em nosso dia a dia. Fonseca (2004, p. 12), ao refletir sobre a Educação Matemática na perspectiva do letramento, reconhece que o processo de letramento é encarregado por oportunizar aos sujeitos diferentes modos de ler o mundo, nos quais a cultura, os conceitos, as relações, os procedimentos e os resultados matemáticos auxiliam na construção das aprendizagens. Enfim,

[...] tomar as práticas de numeramento como práticas de letramento permite-nos ainda valer-nos dos estudos sobre letramento, que contam com uma produção bem mais atentada e amadurecida do que a produção sobre numeramento, no que se refere tanto à elaboração de conceitos e sua mobilização em estudos mais prodigamente replicados e avaliados, quanto à disponibilização de subsídios para a prática pedagógica, forjados a partir de resultados desses estudos (FONSECA, 2009, p.55).

Para pensar o letramento matemático partiremos da perspectiva de letramento de Soares (2009), refletindo sobre as práticas sociais e culturais que circundam a participação dos sujeitos na sociedade. Para tanto, nos próximos tópicos iremos discorrer sobre o Letramento Estatístico, o Letramento Probabilístico e o Letramento Estocástico, unindo o Estatístico com o Probabilístico.

\subsubsection{Letramento Estatístico}

O termo letramento estatístico vai além do conhecimento de conceitos estatísticos, pois refere-se à capacidade crítica de compreender, interpretar e avaliar os resultados estatísticos do nosso cotidiano, e ser capaz de tomar decisões a partir dessas reflexões (GAL, 2002). Desse modo, Gal (2002) mostra-nos que o termo "letramento estatístico" faz referência a dois aspectos inter-relacionados:

[a] à capacidade das pessoas de interpretar e de avaliar criticamente informações estatísticas relacionadas a dados, argumentos ou fenômenos estocásticos, que podem 
encontrar em diversos contextos e quando relevante; e [b] sua capacidade de discutir ou comunicar suas reações a tais informações estatísticas, tais como o significado da informação, suas opiniões sobre as implicações desta informação, ou suas preocupações quanto a aceitabilidade de determinadas conclusões (GAL, 2002, p. 2, tradução nossa). ${ }^{7}$

Se observarmos os dois aspectos, evidenciamos a existência de algumas ações que envolvem o letramento estatístico: interpretar, avaliar, discutir e argumentar. Essa conotação ultrapassa o receber informação, atrelando-se à atuação crítica do sujeito perante as informações estatísticas.

Nesse sentido, o desenvolvimento das capacidades e das habilidades de letramento estatístico não se limita a textos, mas compreende outros elementos como a leitura de gráficos e de tabelas. Segundo Gal (2002), essa leitura circunda as informações sobre o contexto em que os sujeitos estão inseridos, incluindo as práticas sociais e culturais que ocorrem na sociedade. Assim, mesmo a criança pequena não está alheia a esse contexto social, uma vez que o mundo que a rodeia está repleto de informações e práticas sociais do mundo estatístico, exigindo dela um processo de interpretação.

\subsubsection{Letramento Probabilístico}

O letramento probabilístico refere-se ao conhecimento de conceitos probabilísticos, isto é, fenômenos de aleatoriedade que permeiam o nosso dia a dia, como as noções de probabilidades que envolvem os riscos, as chances e as incertezas. Nesse sentido, o contexto e o conhecimento de mundo do indivíduo influenciam na percepção da probabilidade, bem como a capacidade de entender, manipular ou analisar de forma crítica a informação (GAL, 2005).

Ser letrado em assuntos relacionados à probabilidade requer que a pessoa desenvolva algum conhecimento não só de ideias relevantes e maneiras para descobrir probabilidades, e a linguagem do acaso, mas também do papel dos processos probabilísticos e das comunicações no mundo (GAL, 2005, p. 58, tradução nossa). ${ }^{8}$

Para proporcionar o letramento probabilístico, é fundamental a produção da criticidade que envolve o exercício de questionamentos acerca da informação dentro do contexto sociocultural em que os sujeitos estão introduzidos (GAL, 2005). Por conseguinte, no letramento probabilístico com base na informação, o indivíduo percebe a variação, a aleatoriedade, a incerteza, o acaso e a chance a partir da compreensão do contexto.

\footnotetext{
${ }^{7}$ people's ability to interpret and critically evaluate statistical information data-related arguments, or stochastic phenomena, which they may encounter in diverse contexts, and when relevant (b) their ability to discuss or communicate their reactions to such statistical information, such as their understanding of the meaning of the information, their opinions about the implications of this information, or their concerns regarding the acceptability of given conclusions. (GAL, 2002, p. 2).
}

${ }^{8}$ Being literate about probability-related matters requires that a person develops some knowledge not only of relevant big ideas, ways to figure probabilities, and the language of chance, but also of the role of probabilistic processes and communications in the world (GAL, 2005, p. 58). 
Em nossa concepção, essa conotação do letramento permite às crianças compreenderem que o pensamento matemático não é necessariamente exato, bem como que muitos eventos aleatórios, mesmo não sendo premeditados, podem ser investigados e pensados a partir de suas possibilidades de ocorrência.

\subsubsection{Letramento Estocástico}

A partir do olhar desta pesquisa, o letramento estocástico permite a junção do letramento estatístico com o letramento probabilístico. Nesse sentido, Lopes (1998) salienta que a expressão "estocástica" surgiu na Europa com o intuito de articular os estudos da estatística com a probabilidade. Portanto, a respeito da estocástica, a autora afirma que:

[...] o ensino interdisciplinar da Estocástica poderá proporcionar aos alunos uma aquisição de conhecimentos menos compartimentalizados, através de experiências que lhe permitam fazer observações e tirar conclusões, desenvolvendo, assim, seu pensamento científico, fundamental para sua formação (LOPES, 1998, p. 10).

Para refletirmos sobre o letramento estocástico, partimos das ideias de percepção e análise do contexto e a da criticidade abordadas por Gal $(2002,2005)$ nos letramentos estatístico e probabilístico. Observar o contexto para compreender as informações que nos rodeiam envolve aspectos culturais e sociais, que irão contribuir para a formação de um cidadão ativo e crítico na sociedade.

Lopes (2013, p.76), ao tratar de criticidade, afirma que "o trabalho com a estocástica deve auxiliar a escola em seu papel de preparar os estudantes para a realidade, na medida em que, ao fazer a análise de situações diversas que envolvem a incerteza, promove o desenvolvimento do raciocínio crítico" (p. 76). Nessa perspectiva, vemos que o letramento estocástico, o trabalho com a estatística e a probabilidade, oportuniza a construção de um comportamento crítico dos alunos.

Outro aspecto importante de ser pensado no letramento estocástico é a interdisciplinaridade (LOPES, 1998), o que exige na prática pedagógica um trabalho que dialoga com outras áreas e disciplinas, proporcionando a construção de um conhecimento mais holístico e transversal. Assim, o objetivo do letramento estocástico é desenvolver a postura crítica do cidadão para atuar de forma ativa dentro da sociedade. Lopes (1998, p. 15) aponta que "a Estatística e a Probabilidade são temas essenciais da educação para a cidadania, uma vez que possibilitam o desenvolvimento de uma análise crítica sob diferentes aspectos científicos, tecnológicos e/ou sociais".

Assim, podemos definir letramento estocástico como o conjunto de habilidades que encontramos no letramento estatístico e no letramento probabilístico, ou, melhor dizendo, as percepções de variação, de contexto, de incerteza, de aleatoriedade, do acaso, e interpretação de informações nas práticas sociais em nosso cotidiano.

Nesse sentido, consideramos que práticas pedagógicas na Educação Infantil, focalizadas no letramento estocástico, podem promover um olhar crítico e reflexivo de crianças sobre as rotinas culturais que a cercam, potencializando novas formas de pensar a realidade da infância. 


\section{Abordagem metodológica}

Para elaboração deste trabalho, utilizou-se uma pesquisa de abordagem qualitativa, tratando-se, mais especificamente, de uma análise documental, realizada no período de dezembro de 2020 a fevereiro de 2021. Essa modalidade de pesquisa baseia-se em documentos como material primordial, extraindo deles a análise, organizando-os e interpretando-os segundo os objetivos da pesquisa (PIMENTEL, 2001).

No nosso caso, o material consiste na BNCC de Educação Infantil e o objetivo é analisar possíveis aproximações e potencialidades para o trabalho com o pensamento e o raciocínio estocástico com os objetivos de aprendizagem e desenvolvimento (OAD) presentes na BNCC de Educação Infantil.

A coleta de dados se deu a partir dos Objetivos de Aprendizagem e Desenvolvimento do referido documento. Para estes, mantemos as siglas presentes na BNCC. Para os itens apresentados anteriormente, fez-se uma leitura prévia, criando interações iniciais com o pensamento estocástico, que serviram para orientar a segunda leitura, mais aprofundada. A análise de dados foi estruturada de modo a apontar possibilidades didático-metodológicas que são potencializadas pelos OAD.

\section{Raciocínio e Pensamento Estocástico na Educação Infantil: associações com a BNCC}

Neste instante, adentraremos no campo da estocástica para a Educação Infantil. Assim, é necessário analisar como podemos trabalhar o raciocínio e o pensamento estocástico com as crianças pequenas. Lopes (2012) discute a educação estocástica na infância, partindo do entendimento de pensamento e de raciocínio.

O raciocínio estatístico centra-se na variabilidade, nas relações sobre o problema investigado e na elaboração e construção da análise de dados. Já o raciocínio combinatório pauta-se na separação e arranjo em conjuntos. E, por fim, o raciocínio probabilístico liga-se à possibilidade ao analisar a chance e fazer previsões sobre acontecimentos. Essas três formas de raciocínio interligadas compõem o raciocínio estocástico (LOPES, 2012).

Para problematizar o pensamento estocástico e incentivar o processo investigativo das crianças, Lopes (2012) afirma que é preciso respaldar-se na cultura infantil. A criança tem necessidade de criar e recriar conhecimentos, ampliar a imaginação e a criatividade, por isso é significativo explorar experimentos de aleatoriedade e estimativa, vivências de coletar, representar e analisar dados dentro do contexto infantil. Nesse sentido, o trabalho com o pensamento estocástico envolve fenômenos aleatórios, interpretação de amostras e produção de inferências que expandem as competências e as potencialidades das crianças (LOPES, 2012).

Se voltarmos à BNCC, que discute a importância de despertar a criatividade e a curiosidade das crianças pequenas a partir de elementos socioculturais (BRASIL, 2017), visualizamos que o raciocínio e o pensamento estocástico podem configurar experiências de observação, manipulação de objetos, investigação, levantamento de hipóteses e sondagem de 
informações, capazes de colocar a criança diante de conhecimentos matemáticos, aumentando as vivências infantis e o senso crítico.

O trabalho pedagógico com raciocínio e pensamento estocástico na Educação Infantil requer que busquemos um alicerce nas orientações da BNCC (BRASIL, 2017). A seguir, iremos pensar em objetivos de aprendizagem e desenvolvimento (OAD) que se articulam com a estocástica para crianças pequenas de 4 anos a 5 anos e 11 meses em dois campos de experiência: (a) escuta, fala, pensamento e imaginação; e (b) espaços, tempos, quantidades, relações e transformações.

Quadro 1 - Objetivos de Aprendizagem e Desenvolvimento

\begin{tabular}{|c|c|c|}
\hline $\begin{array}{c}\text { CAMPO DE } \\
\text { EXPERIÊNCIA }\end{array}$ & OAD & JUSTIFICATIVA \\
\hline \multirow{2}{*}{$\begin{array}{l}\text { Escuta, fala, } \\
\text { pensamento e } \\
\text { imaginação }\end{array}$} & $\begin{array}{l}\text { "(EI03EF01) Expressar ideias, } \\
\text { desejos e sentimentos sobre } \\
\text { suas vivências, por meio da } \\
\text { linguagem oral e escrita } \\
\text { (escrita espontânea), de fotos, } \\
\text { desenhos e outras formas de } \\
\text { expressão" (BRASIL, 2017, p. } \\
\text { 49). }\end{array}$ & $\begin{array}{l}\text { O objetivo se aproxima do trabalho com a } \\
\text { estocástica por visar a expressão dos } \\
\text { pensamentos das crianças, seja pelo uso da } \\
\text { oralidade ou de outras maneiras de comunicar-se. }\end{array}$ \\
\hline & \begin{tabular}{lcr} 
"(EI03EF07) & Levantar \\
hipóteses & sobre gêneros \\
textuais & veiculados em \\
portadores & \multicolumn{2}{c}{ conhecidos, } \\
recorrendo a estratégias de \\
observação gráfica e/ou de \\
leitura" (BRASIL, 2017, p.50).
\end{tabular} & $\begin{array}{l}\text { O objetivo se relaciona com a estocástica no } \\
\text { momento em que a criança observa e faz a leitura } \\
\text { de um gráfico ou uma tabela, por exemplo, na } \\
\text { tentativa de identificar informações ou até mesmo } \\
\text { ao organizar as informações encontradas. }\end{array}$ \\
\hline \multirow[b]{3}{*}{$\begin{array}{l}\text { Espaços, tempos, } \\
\text { quantidades, relações e } \\
\text { transformações }\end{array}$} & $\begin{array}{l}\text { "(EI03ET03) Identificar e } \\
\text { selecionar fontes de } \\
\text { informações, para responder a } \\
\text { questões sobre a natureza, seus } \\
\text { fenômenos, sua conservação" } \\
\text { (BRASIL, 2017, p. 51). }\end{array}$ & $\begin{array}{l}\text { O objetivo tem relação com a estocástica, visto } \\
\text { que, para que a criança participe do processo } \\
\text { investigativo em relação a um problema, } \\
\text { precisará buscar e selecionar informações para } \\
\text { analisar os dados, e posteriormente organizá-los. }\end{array}$ \\
\hline & $\begin{array}{l}\text { "(EI03ET04) Registrar } \\
\text { observações, manipulações e } \\
\text { medidas, usando múltiplas } \\
\text { linguagens (desenho, registro } \\
\text { por números ou escrita } \\
\text { espontânea), em diferentes } \\
\text { suportes" (BRASIL, 2017, p. } \\
\text { 51). }\end{array}$ & $\begin{array}{l}\text { O objetivo contempla os registros do trabalho } \\
\text { com o raciocínio estatístico, combinatório e } \\
\text { probabilístico, ou seja, as diferentes formas que a } \\
\text { criança irá utilizar para comunicar o seu } \\
\text { pensamento. }\end{array}$ \\
\hline & $\begin{array}{l}\text { "(EI03ET05) Classificar } \\
\text { objetos e figuras de acordo } \\
\text { com suas semelhanças e } \\
\text { diferenças” (BRASIL, 2017, p. } \\
\text { 51). }\end{array}$ & $\begin{array}{l}\text { O objetivo abrange os elementos do raciocínio } \\
\text { combinatório, a construção de grupos diferentes } \\
\text { com os mesmos elementos, critério de conjuntos: } \\
\text { espessura, forma, cor, peso, etc. }\end{array}$ \\
\hline
\end{tabular}




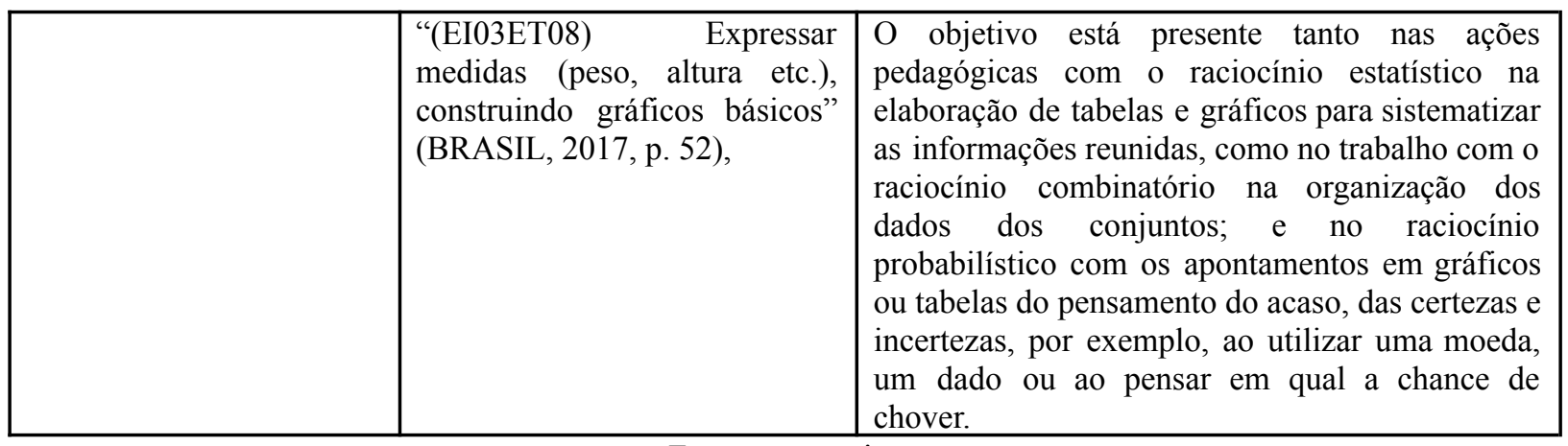

Fonte: a pesquisa

Destacamos os objetivos de aprendizagem e desenvolvimento dos $4^{\circ}$ e $5^{\circ}$ campos de experiência da Base Nacional Comum Curricular para a Educação Infantil (2017) e buscamos explicar cada um deles, aproximando-os da estocástica. Dessa maneira, conseguimos lançar um olhar sobre as habilidades apresentadas na BNCC e relacioná-las com o pensamento estocástico, que está associado com os conteúdos de Combinatória, Estatística e Probabilidade do currículo de Matemática.

Sendo assim, entendemos que é necessário o desenvolvimento do pensamento estocástico nas crianças pequenas para que compreendam o mundo a sua volta e saibam organizar as informações através de tabelas, gráficos e outras formas de registros. O trabalho lúdico com o acaso, eventos cotidianos e aleatórios; a compreensão dos elementos de combinatória; bem como o processo de investigação, observação, coleta, representação e análise de dados dentro do contexto das crianças desperta a curiosidade, favorece a criticidade, o pensamento, o raciocínio e as decisões das mesmas, proporcionando o avanço de sua aprendizagem.

\section{Considerações Finais}

No presente artigo tivemos como objetivo analisar possíveis aproximações e potencialidades sobre o trabalho com o pensamento e raciocínio estocástico com os objetivos de aprendizagem e desenvolvimento (OAD) presentes na BNCC de Educação Infantil. Nossos resultados apontam que a BNCC (BRASIL, 2017) apresenta e discute a importância de despertar a criatividade e a curiosidade das crianças na educação infantil a partir de elementos socioculturais com base na cultura infantil, conforme apontados por Lopes (2012). A partir da concepção de Lopes (2012) de que a educação estocástica na infância se dá a partir do entendimento de pensamento e de raciocínio, por meio do processo investigativo, apontamos que esse trabalho pedagógico pode ser desenvolvido a partir das orientações da BNCC, a partir dos objetivos de aprendizagem e desenvolvimento (OAD) para a Educação Infantil. Destacamos, ainda, que esse processo investigativo pode ocorrer por meio de experiências de observação, manipulação de objetos, investigação, levantamento de hipóteses e sondagem de informações, capazes de colocar a criança diante de conhecimentos matemáticos, aumentando as vivências infantis e o senso crítico.

O raciocínio e o pensamento estocástico para as crianças dessa modalidade de ensino se configuram na BNCC por meio de dois campos de experiência: (a) escuta, fala, pensamento e imaginação; e (b) espaços, tempos, quantidades, relações e transformações. Os objetivos que compõem o campo de experiência "escuta, fala, pensamento e imaginação", 
(EI03EF01) e (EI03EF07), permitem-nos apontar que o primeiro se aproxima do trabalho com a estocástica por visar a expressão dos pensamentos das crianças, seja pelo uso da oralidade ou de outras maneiras de comunicar-se; o segundo relaciona-se com a estocástica no momento em que a criança observa e faz a leitura de um gráfico ou uma tabela, por exemplo, na tentativa de identificar informações ou até mesmo ao organizar as informações encontradas.

No campo de experiência "espaços, tempos, quantidades, relações e transformações", identificamos quatro objetivos de aprendizagem e desenvolvimento (EI03ET03; EI03ET04; EI03ET05 e EI03ET08). A relação do primeiro com a estocástica se dá na medida em que a criança participa do processo investigativo em relação a um problema, e precisará buscar e selecionar informações para analisar os dados, e posteriormente organizá-los. A relação do segundo com a estocástica se dá a partir dos registros do trabalho com o raciocínio estatístico, combinatório e probabilístico, ou seja, as diferentes formas que a criança irá utilizar para comunicar o seu pensamento. No terceiro objetivo a relação com a estocástica abrange uma habilidade com elementos do raciocínio combinatório, a construção de grupos diferentes com os mesmos elementos, critério de conjuntos: espessura, forma, cor, peso, etc. No quarto objetivo, a relação com estocástica está presente tanto nas ações pedagógicas com o raciocínio estatístico na elaboração de tabelas e gráficos para sistematizar as informações reunidas, como no trabalho com o raciocínio combinatório na organização dos dados dos conjuntos; e no raciocínio probabilístico com os apontamentos em gráficos ou tabelas do pensamento do acaso, das certezas e incertezas, por exemplo, ao utilizar uma moeda, um dado ou ao pensar em qual a chance de chover.

A busca de possíveis aproximações e potencialidades sobre o trabalho com o pensamento e raciocínio estocástico com os objetivos de aprendizagem e desenvolvimento (OAD) presentes na BNCC permitiu-nos visualizar que essa aproximação é possível a partir dos $4^{\circ}$ e $5^{\circ}$ campos de experiência da Base Nacional Comum Curricular para a Educação Infantil, e que está associado com os conteúdos de Combinatória, Estatística e Probabilidade do currículo de Matemática.

O estudo aqui apresentado permite-nos apontar, ainda, a importância do desenvolvimento do pensamento estocástico nas crianças pequenas para que compreendam o mundo a sua volta e saibam organizar as informações através de tabelas, gráficos e outras formas de registros. Como potencialidades, podemos destacar que os objetivos de aprendizagem e desenvolvimento (OAD) presentes na BNCC apresentam-se como fortes possibilidades didático-metodológicas para o trabalho lúdico com o acaso, os eventos cotidianos e aleatórios; a compreensão dos elementos de combinatória; bem como o processo de investigação, observação, coleta, representação e análise de dados dentro do contexto das crianças. E destacamos ainda que a junção do letramento estatístico com o letramento probabilístico, a partir da articulação dessas tais experiências, da percepção, da análise do contexto e a da criticidade, evidenciadas por Gal (2002, 20005), podem levar ao letramento estocástico, conforme ressalta Lopes (1998).

Além disso, o letramento estocástico pode desenvolver habilidades para uma postura crítica do cidadão para atuar de forma ativa dentro da sociedade, pois, como destaca Lopes (1998, p. 15), "a Estatística e a Probabilidade são temas essenciais da educação para a cidadania, uma vez que possibilitam o desenvolvimento de uma análise crítica sob diferentes aspectos científicos, tecnológicos e/ou sociais". Ou seja, os objetivos de aprendizagem e desenvolvimento (OAD) presentes na BNCC podem proporcionar uma aprendizagem com 
mais sentido e significado para as crianças, na medida em que buscam despertar a curiosidade e favorecer a criticidade, o pensamento, o raciocínio, nas tomadas de decisões.

As análises realizadas a partir do presente estudo despertaram-nos alguns questionamentos sobre o olhar do professor para as aproximações aqui apresentadas, bem como acerca das percepções sobre o pensamento estocástico que as crianças da Educação Infantil teriam a partir das possibilidades didático-metodológicas destacadas pela BNCC. Mas esses são assuntos para uma próxima pesquisa!

\section{Referências}

ARIÈS, Philippe. História Social da Criança e da Família. 2. ed. Rio de Janeiro: LTC, 1981.

BRASIL. Constituição Federal de 1988. Constituição da República Federativa do Brasil de 1988. Brasília, 5 de outubro de 1988.

BRASIL. Lei n. 9.394. Estabelece as Diretrizes e Bases da Educação Nacional. Diário Oficial da União, Brasília, 20 de dezembro de 1996.

BRASIL. Ministério da Educação e do Desporto. Secretaria de Educação Fundamental. Referencial Curricular Nacional para a Educação Infantil. Brasília: MEC/SEF, 1998.

BRASIL. Ministério da Educação. Diretrizes Curriculares Nacionais Para a Educação Infantil. Brasília: SEB, 2010.

BRASIL. Ministério da Educação. Base Nacional Comum Curricular: Educação é a Base. Brasília: MEC, 2017.

BRASIL. Secretaria de Educação Básica. Pacto Nacional pela Alfabetização na Idade Certa: apresentação. Brasília: MEC/SEB, 2014.

CORSARO, William A. Sociologia da Educação. Porto Alegre: Artmed, 2011.

FONSECA, Maria da Conceição Ferreira Reis. A educação matemática e a ampliação das demandas de leitura escrita da população brasileira. In: FONSECA, M. C. F. R. (org.). Letramento no Brasil: habilidades matemáticas. São Paulo: Global, 2004. p. 11-24.

FONSECA, Maria da Conceição F.R. Conceito(s) de numeramento e relações com o letramento. In: LOPES, C.E.; NACARATO, A. M. (org.). Educação matemática, leitura e escrita: armadilhas, utopias e realidade. Campinas, SP: Mercado de Letras, 2009. p. 47-60.

FONSECA, M. C. F. R. Prefácio. In: NACARATO, A. M.; LOPES, C. E. (org.). Indagações, reflexões e práticas em leituras e escritas na educação matemática. Campinas: Mercado de Letras, 2013. p. 7-9.

GAL, Iddo. Adult's Statistical Literacy: Meanings Components, Responsibilities.

International Statistical Review, v. 70, n. 1, 2002. p. 1-25. 
GAL, Iddo. Towards "Probability Literacy" for all citizens: building blocks and instructional dilemmas. In: JONES, Graham A. (ed.). Exploring probability in school: Challenges for teaching and learning. USA: Springer Science and Business Media, 2005.

KUHLMANN Jr. Moysés. Histórias da educação infantil brasileira. São Paulo: Revista Brasileira de Educação, maio-ago., n. 14, 2000.

LOPES, Celi E. A probabilidade e a estatística no ensino fundamental: uma análise curricular. Dissertação (Mestrado) - Universidade Federal de Campinas, Campinas: 1998.

LOPES, Celi E. A Educação Matemática na Infância. Revista Eletrônica de Educação, v. 6, n. 1, mai. 2012.

LOPES, Celi E. A análise exploratória de dados na infância: uma conexão entre a educação estatística e a literatura infantil. In: COUTINHO, C. Q. S. Discussões sobre o ensino e a aprendizagem da probabilidade e da estatística na escola básica. Campinas: Mercado de Letras, 2013.

MARCHI, R. C. As teorias da socialização e o novo paradigma para os estudos sociais da infância. Educação \& Realidade, v. 34, n.1, 2009. p. 227-246.

PIMENTEL, A. O método da análise documental: Seu uso numa pesquisa historiográfica. Cad. Pesquisa, v.114, n.4, 2001, 179-95.

RIO GRANDE DO SUL. Secretaria de Estado da Educação. Referencial Curricular Gaúcho: Educação Infantil. Porto Alegre: SE/DP, 2018.

SOARES Magda. Letramento e Escolarização. In: RIBEIRO, V. (Org.). Letramento no Brasil. São Paulo: Global, 2003.

SOARES, Magda. Letramento: um tema em três gêneros. Belo Horizonte: Autêntica, 2009.

Recebido em março de 2021.

Aprovado em maio de 2021. 